\title{
Malaria Prevalence and Treatment Seeking Behaviour of Campus Students in Mkpat Enin, Akwa Ibom State, Nigeria
}

\author{
Lydia E. Udofia $^{1^{*}}$, Florence Z. Uyanga ${ }^{2}$ and Eunice B. Ogunkelu ${ }^{3}$ \\ ${ }^{1}$ Department of of Zoology, Akwa Ibom State University, Faculty of Biological Sciences, Mkpat \\ Enin, Akwa Ibom State \\ ${ }^{2}$ Department of Microbiology, Akwa Ibom State University, Faculty of Biological Sciences, \\ Mkpat Enin, Akwa Ibom State. \\ ${ }^{3}$ Department of Health Promotion and Education, Faculty of Public Health, University of Iba- \\ dan, Oyo State.
}

*Correspondence should be addressed to Lydia E. Udofia: lydiaetuk@gmail.com

Received 1st June 2021; Revised 28th September 2021; Accepted 29th September 2021

(C) 2021 Udofia et al. Licensee Pan African Journal of Life Sciences an official publication of Faculty of Basic Medical Sciences, Ladoke Akintola University of Technology, Ogbomoso. This is an Open Access article distributed under the terms of the Creative commons Attribution License (https://creativecommons.org/licenses/BY/4.0), which permits unrestricted use, distribution, and reproduction in any medium, provided the original work is properly cited.

\begin{abstract}
Background: Malaria is still thriving despite efforts to eradicate the disease. This study aimed to determine the prevalence of malaria and treatment-seeking behaviour among university students in IkotAkpaden campus of Akwa Ibom State University

Methods: A cross-sectional study on 700 undergraduate students randomly selected was carried out between July to December 2017 in Akwa Ibom State University. Structured questionnaires were administered to collect data. Microscopy and Rapid Diagnostic Tests (RDT) were done to determine parasitaemia for students who voluntarily consented to be tested. Chi-square test at $\mathrm{P}<0.05$ was used to evaluate the prevalence of malaria and the differences in the student's attitude on malaria treatment and prevention practices.

Results: Of the 500 students who filled the questionnaire, 100 students consented to undergo the test, 56 (56\%) were males, while 44 (44\%) were females. Only15 students (17.86\%) were positive for both microscopy and RDT. Malaria prevalence by microscopy (84\%) was significantly higher than RDT (27\%). Fever and headache were the most common symptoms recorded. RDT had a sensitivity of $17.86 \%$, a specificity of $25 \%$, a positive predictive value of $55.56 \%$, and a negative predictive value of $5.48 \%$.

Conclusion: This study revealed a higher prevalence of malaria by microscopy than RDT among the students, indicating that the use of RDTs is limited. RDTS may have more usefulness in remote areas, but microscopy remains the reference technique. Overall, $96.2 \%$ knew about malaria while $85.3 \%$ knew mosquito bites cause malaria. The majority, $69.2 \%$, of participants go for malaria test as the first action when malaria is suspected, $83 \%$ use antimalarial combination therapy medication, and $62.6 \%$ sought treatment of malaria immediately. .
\end{abstract}

Keywords: Malaria, Treatment seeking behaviour, Microscopy, Rapid diagnostic test, Nigeria. 


\subsection{INTRODUCTION}

Malaria, a prevalent disease spread by infectious female Anopheles mosquitoes, is caused by parasites that belong to the genus Plasmodium. Five species affect humans, $P$. falciparum. $P$. ovale, $P$. vivax, $P$. malariae, and $P$. knowlesi. Malaria is prevalent in the tropics and subtropics due to suitable environmental conditions such as stagnant water, warm temperature, and rainfall, which favor the reproduction and spread of the vectors that transmit malaria parasites. Malaria incidence is reported to have decreased globally by $18 \%$, as reported by World Health Organization [1,2]. Nigeria suffers the world's most significant malaria burden, with approximately 51 million cases and 207,000 deaths reported annually (approximately $30 \%$ of the total malaria burden in Africa), while $97 \%$ of the total population (approximately 173 million) is at risk of infection [2]. Out of the 91 countries that reported indigenous malaria cases in 2016, 15 countries within sub-Saharan Africa, except India, are responsible for $80 \%$ of the global malaria burden [2]. Epidemiology and clinical manifestation of malaria vary widely in different parts of the world. This is due to Plasmodium species occurring in different regions, their susceptibility to commonly used drugs, and the level of acquired immunity amongst the human population. There is a need for continuous awareness and application of protective measures to reduce the infection rate. Many studies on malaria have been done in Nigerian hospitals and rural areas [3-8] and among students [9-15]. Continuous study on malaria knowledge, attitude, and practices are necessary in the university campuses, which serve as a potential reservoir of infectious diseases because of the large population living closely for an extended period. This study aimed to investigate the prevalence of malaria among students, diagnostic outcomes using microscopy and RDT kits, and determine these students' malaria treatment-seeking behavior.

\subsection{METHODOLOGY}

\subsection{Study Area and Participants}

The study took place in Akwa Ibom State University, Ikot Akpaden Campus, Mkpat Enin Local Government Area, Akwa Ibom State. Ikot Akpaden is situated between latitude $4^{\circ} 35^{\prime} \mathrm{N}$ and $4^{\circ} 40^{\prime} \mathrm{N}$ of the equator and $7^{\circ}$ $45^{\prime} \mathrm{E}$ and $7^{\circ} 50^{\prime} \mathrm{E}$ of the Greenwich Meridian (Figure 1). The campus is well laid out, leading to departments and offices. Students reside off campus around the University in Ekim, Ikot Akpaden, Ikot Oyoro, Ikot Obio Ndoho and

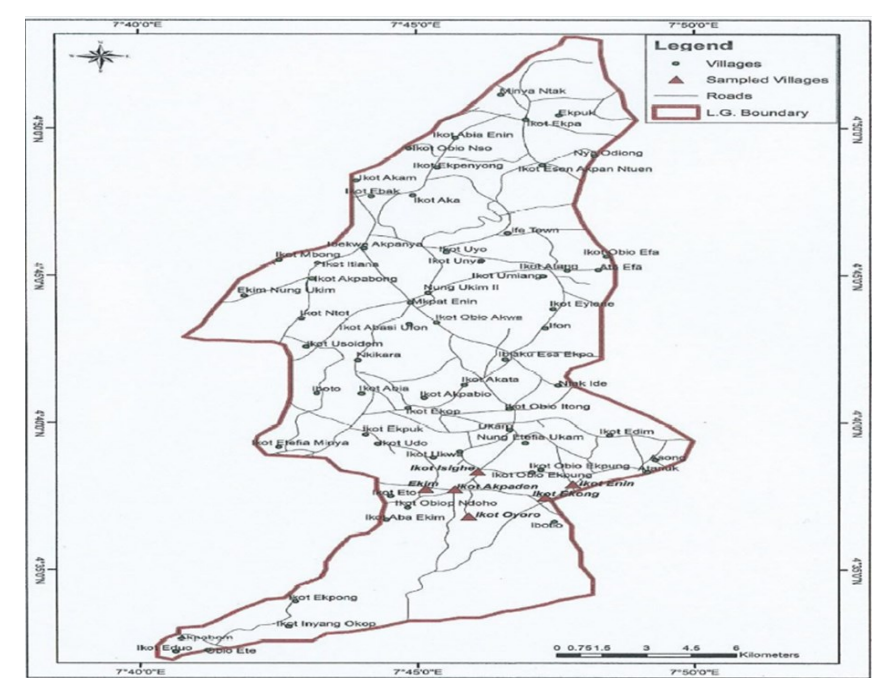

Figure 1. Map of Mkpat Enin LGA, Akwa Ibom State showing sampled areas.

others. From observation, these are densely populated rural areas with clustering of houses and bushes without tarred roads. There is a lot of natural vegetation and farms around these houses. Potholes and gutters abound all around leading to accumulation of stagnant water, a good breeding ground for mosquitoes. Rearing season begins in March and can last into December. This study was carried out between January-December, 2017. Volunteers were selected by simple random sampling; male and female undergraduate students aged 16-35 years living in residences around campus.

\subsection{Ethical Approval}

This study was approved by the Ethical Review Committee of the Department of Biological Sciences, Akwa Ibom State University (AKSU/99/VolVi/200). After simple random sampling for selecting participants, verbal consent was obtained from each individual before collecting the blood sample. Students who gave their consent to participate in the study, whether they showed symptoms of malaria or not, were included in the study. Students who were on anti-malarial drugs two weeks before or at the time of sampling were excluded.

\subsection{Study Design}

A questionnaire on knowledge, attitude, and treatment practices on malaria was administered to 700 volunteers to determine their history of malaria, treatment-seeking behavior, and practices. Only five hundred (500) questionnaires were returned. Out of the 500 questionnaires that were returned, only100 students 
voluntarily agreed to be tested. Blood samples were obtained after consent had been given by participants.

\subsection{Blood Sample Collection and Malaria Parasite Screening}

About 1-2 drops of blood (1-2 drops) were obtained by finger pricking disposable lancets from the index finger onto a clean slide to prepare a thin and thick blood smear. Slides of the peripheral blood specimens were made immediately after collection on a clean, grease-free microscope slide and allowed to air dry. The films were stained with $10 \%$ Giemsa solution for $10 \mathrm{~min}$ and examined by microscopists. The slides were allowed to air dry and subsequently examined by light microscopy using an oil immersion objective lens. A slide was declared negative only after observing 100 microscopic fields without finding parasites. For each specimen, the thick films were examined first for the detection of malaria parasites, followed by the thin films for speciation. Two microscopists examined the slides. Each microscopist examined the slides independently and the results were recorded as positive when both recorded a positive result and the same species. The Pf Histidinerich protein (HRP)-II (Standard Diagnostics Inc., SD Bioline) Antigen rapid test was used for the rapid diagnosis of malaria. The test cassette was removed from the foil pouch and then placed on a leveled surface. $5 \mu 1$ of whole blood was slowly added into the sample well (A) with the aid of a capillary tube, followed by 2 drops of clearing buffer in the buffer well (B). Samples were interpreted as positive when rose pink bands were visible in both the control and test regions. In contrast, samples were considered negative when the rose pink color was visible in the control region, and no colour band appeared in the test region.

\subsection{Data Analysis}

Socio-demographic characteristics, attitudes, practices, and treatment-seeking behaviour were treated as categorical variables and presented as frequencies and percentages. Data were analysed using the Chi-square test to evaluate the prevalence of malaria at a $p<0.05$ level of confidence using Statistical Package for the Social Sciences (SPSS version 19) software packages.

\subsection{RESULTS}

3.1 Sociodemographic Characteristics of Respondents $(\mathbf{n}=\mathbf{5 0 0})$
Of the Five hundred (500) questionnaires retrieved, 278 $(55.6 \%)$ were males and 222 (44.4\%) females, giving an approximate equivalence of participation based on gender (Table 1). The age range of respondents was 16-35 years, with 15-20 years having the highest number 215 (43\%) of respondents. Residents of Ekim were 139 (27.8\%), Ikot Akpaden 221 (44.2\%), Ikot Oyoro 50 $(10 \%)$ and Ikot Obio Ndoho 59 (11.8\%). Students who lived in other residential areas were $31(6.2 \%)$

Table 1. Sociodemographic Characteristics of the Respondents $(n=500)$

\begin{tabular}{lll}
\hline Variables & $\begin{array}{l}\text { No. exam- } \\
\text { ined }\end{array}$ & \% of respondent \\
Age group & & \\
$15-20$ & 215 & 43 \\
$21-25$ & 180 & 36 \\
$26-30$ & 90 & 18 \\
$31-35$ & 15 & 3 \\
Gender & & \\
Male & 278 & 55.6 \\
Female & 222 & 44.4 \\
Level & & \\
100 & 60 & 12 \\
200 & 140 & 28 \\
300 & 30 & 6 \\
400 & 180 & 36 \\
500 & 90 & 18 \\
Residence & & \\
IkotAkpaden & 221 & 44.2 \\
Ekim & 139 & 27.8 \\
IkotOyoro & 50 & 10 \\
IkotObioNdoho & 59 & 11.8 \\
Others & 31 & 6.2 \\
\hline
\end{tabular}

3.2 Prevalence of malaria $(n=100)$

The prevalence of malaria by microscopy 84 (84\%) was significantly higher than that of Rapid Diagnostic test 27 (27\%). Only 15 students were positive both for microscopy and RDT, while 4 (4) tested negative to microscopy and RDT, as shown in Table 2. RDT showed a sensitivity of $17.86 \%$, a specificity of $25 \%$, a positive predictive value of $55.56 \%$, and a negative predictive value of $5.48 \%$. All infections were of Plasmodium falciparum. The prevalence of malaria was similar between males and females ( 78.6 vs. $90.9 \%$ by microscopy and 23.2 vs. 31.8 by RDT; $\left(\chi^{2}\right)=0.14, \mathrm{p}>0.05$ ). Prevalence according to location showed no significant difference $\left(\chi^{2}\right)=1.34, \mathrm{p}$ $>0.05)$. There was no significant difference among age groups, $\left.\left(\chi^{2}\right)=0.80, \mathrm{p}>0.05\right)$ with aged $20-24$ having the 
highest prevalence (86.8\%), followed by aged $15-19$ years $(83.3 \%)$ and aged $25-30$ years $(76.9 \%)$ (Table 3 ).

Table 2. Comparison Between Microscopy and RDT Results

\begin{tabular}{llll}
\hline & & $\begin{array}{l}\text { Microscopy n } \\
(\mathbf{\%})\end{array}$ & \\
\hline & Positive & Negative & Total \\
RDT n (\%) & & & \\
Positive & $15(15)$ & $12(12)$ & $27(27)$ \\
Negative & $69(69)$ & $4(4)$ & $73(73)$ \\
Total & $84(84)$ & $16(16)$ & $100(100)$ \\
\hline
\end{tabular}

Table 3. Prevalence of Malaria According to Location, Age and Gender $(\mathrm{n}=100)$

\begin{tabular}{llll}
\hline Variable & $\begin{array}{l}\text { No exam- } \\
\text { ined }\end{array}$ & $\begin{array}{l}\text { Microscopy } \\
\text { positive(\%) }\end{array}$ & $\begin{array}{l}\text { RDT } \\
\text { positive } \\
\text { (\%) }\end{array}$ \\
\hline $\begin{array}{l}\text { Location } \\
\text { IkotAkpaden }\end{array}$ & 59 & $51(86.4)$ & $19(32.2)$ \\
Ekim & 20 & $16(80)$ & $3(15)$ \\
IkotOyoro & 7 & $5(71.4)$ & $1(14.3)$ \\
IkotObioNdoho & 9 & $7(77.8)$ & $2(22.2)$ \\
Others & 5 & $5(100)$ & $2(40)$ \\
$\chi^{2}$ & 1.34 & & \\
Age groups(years) & & & $3(50)$ \\
$15-20$ & 6 & $5(83.3)$ & $18(26.5)$ \\
$21-25$ & 68 & $59(86.8)$ & $6(23.1)$ \\
$26-30$ & 26 & $20(76.9)$ & \\
$\chi^{2}$ & 0.80 & & $13(23.2)$ \\
Gender & & & $14(31.8)$ \\
Male & 56 & $44(78.6)$ & \\
Female & 44 & $40(90.9)$ & \\
$\chi^{2}$ & 0.14 & & \\
Total & 100 & & \\
\hline
\end{tabular}

\subsection{Malaria Indicators, Attitudes and Practices by Students $(\mathbf{n}=\mathbf{5 0 0})$}

Of the 500 respondents, the majority, 481 (96.2\%), knew

$$
\chi^{2} \text { - Chi square }
$$

malaria, and 417(85.3\%) knew that mosquito bites caused it. Symptoms of malaria include, fever, headache, body pains, colored urine, loss of appetite, bitter taste, and vomiting. Most of the students, 353 (70.6\%), knew they had malaria when they experienced fever. Some others had body pains $(28 ; 5.6 \%)$, coloured urine $(13 ; 2.6 \%)$, headache $(100 ; 20 \%)$, and other symptoms like loss of appetite, bitter taste, and vomiting $(6 ; 1.2 \%)$. Regarding the frequency of malaria attacks, $140(28 \%)$ had malaria once in 3 months, $(90 ; 18 \%)$ had malaria once a month, and $(90 ; 18 \%)$ also once in 6 months. Some students $(75$; $15 \%)$ had malaria once a year, $(65 ; 13 \%)$ had malaria once in 2 months, while (40;8\%) never experienced malaria (Figure 2). Over half of the students $(274 ; 55 \%)$ used long-lasting insecticide-treated bednets as prevention against malaria. Some used insecticides (122; $24.5 \%$ ), closed their doors and windows in the evenings $(50 ; 10 \%)$, applied mosquito repellants $(5 ; 1 \%)$, evacuated stagnant pools around their surroundings $(40 ; 8 \%)$, and used mosquito coil $(7 ; 1.4 \%)$.

3.4 Treatment Seeking Behavior of Students $(n=500)$ Most students $(346 ; 69.2 \%)$ go for malaria tests as their

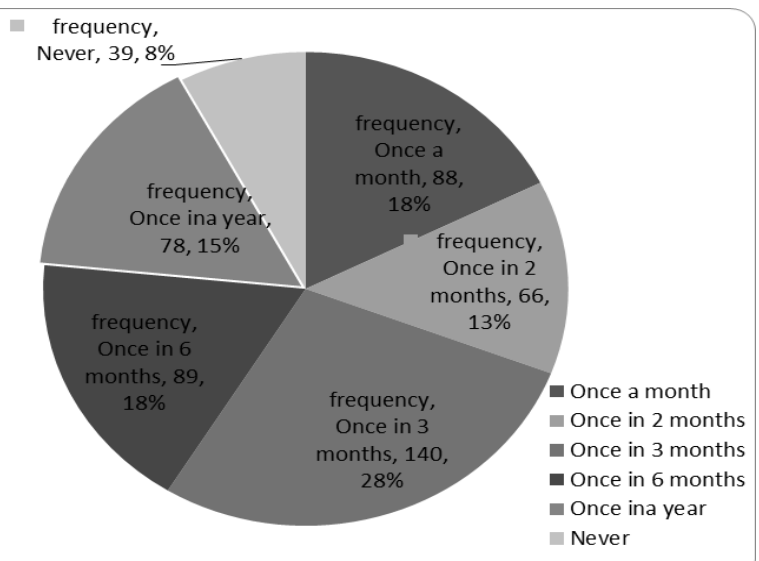

Figure 2. Frequency of malaria attacks $(n=500)$

first action when malaria is suspected (Table 4). Many of the students $(128 ; 25.6 \%)$ take malaria medicine as their first action. A few, $(16 ; 3.2 \%)$ take time to rest while others $(10 ; 1.2 \%)$ visit the hospital to see a doctor. As regards the type of treatment taken, out of the 500 respondents, $(415 ; 83 \%)$ take medicine to treat malaria, 79 $(15.8 \%)$ take herbs and $(6 ; 1.2 \%)$ use other forms of treatment.

Medications taken for malaria include ACTs (antimalarial combination therapy) and non-ACTs. Herbs taken include Azadirachta indica (Dogonyaro), Cymbopogon citratus (Lemon grass), Carica papaya (Pawpaw leaves), Moringa olifera (Miracle plant), and Stachytarpheta augustifolia (Blue snake weed). Treatment for malaria is sought immediately by the majority of the respondents (313; $62.6 \%)$, some after a day $(102 ; 20.4 \%)$, after two days $(52 ; 10.4 \%)$ and others, after three days $(43 ; 8.6 \%)$. The 
majority $(241 ; 48.2 \%)$ got their prescrip- Table 4. Indicators, Attitudes, Practices, and Treatment-seeking Behavior of tion from doctors, $(40 ; 8 \%)$ from nurses, Students

(151; 30.2\%) from the pharmacist, (44; Variables

Total number (\%)

$8.8 \%)$ from patent medicine dealers, and

$(24 ; 4.8 \%)$ took medicines they considered fit for treatment.

Knowledge about cause of malaria

Know malaria

Causes

Mosquito bite

Eating too much oil

Poor personal Hygiene

Others

Symptoms of malaria

Fever

The prevalence of malaria and treatment

Body pains

-seeking behavior was evaluated among students of Akwa Ibom State University.

The institution is situated in a rural area

that is fast developing due to the presence of students and workers living in the community. Newly constructed houses which serve as accommodation are clustered around the community.

Colored urine

Headache

Others

Preventive measures against malaria

Long-lasting Insecticide-treated bed nets (LLIN) Insecticide

Closure of doors and windows

Application of mosquito repellant

Evacuation of stagnant pools of water

Others

The first action taken when malaria is discovered

Go for a malaria test

Take medications

Rest

The findings in this study revealed a

high prevalence of malaria by microscopy $(84 \%)$ than RDT (27\%) among students. This agreed with results from similar studies [10, 17-18, 32, 34]. The high prevalence could be attributed to the non -compliance of students to preventive measures, especially the use of insecticide-treated bed nets, proper disposal of refuse and good sanitary conditions around the living areas. Only 55\% reported the use of LLIN followed by See a doctor

Malaria treatment

Herbs

Medicine

Others

Medications taken when having malaria

ACTs

Non-ACTs

Treatment seeking time

Immediately

After a day

After two days

After 3 days

Medicines usually prescribed by

Doctor

Nurse

Pharmacist

PMD (Patent medicine dealer)

$24.5 \%$ that reported the use of insecti-

Self medication

$481(96.2)$

$417(85.3)$

$18(3.6)$

$50(10)$

$15(3)$

353 (70.6)

28 (5.6)

13 (2.6)

$100(20)$

6 (1.2)

$274(55)$

$122(24.5)$

$50(10)$

5 (1)

$40(8)$

7 (1.4)

$346(69.2)$

$128(25.6)$

$16(3.2)$

10 (2)

$79(15.8)$

$415(83)$

$6(1.2)$

$381(76.2)$

119 (23.8)

$313(62.6)$

$102(20.4)$

$52(10.4 \%)$

$43(8.6 \%)$

$241(48.2 \%)$

$40(8 \%)$

$151(30.2 \%)$

$44(8.8 \%)$

$24(4.8 \%)$ cides. The development of resistance by mosquitoes to these insecticides could lead to a higher infection rate. Some studies conducted in Imo, Nnewi, Edo and Ibadan [9, 19-22] reported unalike results with lower prevalence rates. The variation in prevalence rates in different parts of the country could be attributed to climatic factors like temperature and humidity $[23,24]$ and differences according to malaria's endemicity in different epidemiological zones. The high prevalence could also be attributed to stagnant water bodies due to poor drainage systems, bushy environments, and indiscriminate waste disposal, which contribute to the breeding of mosquitoes. This leads to more individuals being bitten, which leads to more malaria cases. Most of these students go to the class areas to study at night, exposing themselves to mosquito bites. Agriculture and farming activities also contribute to harboring and breeding of mosquitoes [21, 25].

This study reveals a similar infection rate among the male and female respondents, as previously reported in Bayelsa, Kano, and Anambra [5, 17, 19]. The prevalence of malaria was higher in male students compared to females. This difference could be as a result of greater and repeated exposure to mosquito bites due to outdoor activities. Studies on mosquito attraction to humans have shown that these insects are attracted to various compounds secreted by humans like heat, carbon IV oxide $\left(\mathrm{CO}_{2}\right)$, ammonia, lactic acid, and carboxylic acids [26]. Males tend to produce these attractants due to sporting activities in the evenings after lectures. However, other studies contradict this observation [10,27].

This study shows that the prevalence among age groups 
was significantly higher among those aged $21-25$ years $(86.8 \%)$ and $15-20$ years $(83.3 \%)$ as compared to $26-30$ years $(76.9 \%)$. This could be a result of the differences in habits and exposure to the environment. Studies by Andrade et al., [28] noted that gender is among the determinant factors of clinical outcomes of malaria. The lower prevalence in the oldest age group could result from acquired immunity, which might have developed due to previous exposure to malaria infection [29].

Students' knowledge, attitudes, and practices about malaria, findings in this study revealed a high knowledge about malaria $(96.2 \%)$ and its causes $(85.3 \%)$. This is expected as this is a higher institution of learning. The majority are accustomed to fever as a primary symptom $(70.6 \%)$ and the use of LLIN as a preventive measure (55.5\%) against malaria which is in agreement with previous studies [5, 17, 19 - 20]. However, some studies among rural women and caregivers in south west Nigeria show poor knowledge about malaria and its preventive measures [30, 31].

Student's treatment-seeking behavior showed immediate response by most (62.6\%), and the first action taken by most students was to go for a malaria test $(69.2 \%)$. Some take medications $(25.6 \%)$, while a few visit the doctor $(2 \%)$, and others $(3.2 \%)$ take a rest. This indicates that malaria is taken seriously as the majority take a step towards obtaining relief. Malaria is treated by the majority $(83 \%)$ with antimalarial combination therapy medications usually prescribed by a doctor $(48.2 \%)$, a Nurse $(8 \%)$, or a pharmacist (30.2). Few students, (8.8\%) visit patent medicine dealers who are not knowledgeable enough on drugs sold while others $(4.8 \%)$ self-medicate. Some students $(15.8 \%)$ use herbs infused in water.

Our study showed that microscopy yielded a higher prevalence rate than RDT. The low sensitivity rate of RDT $(17.86 \%)$ recorded in this study is lower than previous reports in Nigeria [32, 33]. Microscopy is recommended for all cases of malaria. RDT negative results should be confirmed using microscopy as microscopy remains the gold standard in malaria diagnosis. There is need for intervention using integrated control measures to reduce the prevalence rate of malaria among the students.

Prevalence of malaria is high as revealed in the study. Preventive and control measures will reduce the disease burden.

\section{Acknowledgments}

The authors acknowledge Udeme Ememe, George Utin, Dr. Blessing Umoh, and consenting study participants of Akwa Ibom State University for their support.

\section{Conflicts of Interest}

The authors declare that there are no conflicts of interest regarding the publication of this paper.

\section{Authors' Contributions}

LEU conceived and designed the study, contributed to data collection, data analysis tools, analysis of data and manuscript writing. FZU contributed to study design, data analysis tools and writing of the manuscript. EBO contributed to data analysis tools, Analyzed questionnaires and contributed to manuscript writing. All authors approved the final copy of the manuscript.

\section{References}

1. World malaria report, 2019. World Health organization; 2019

2. World malaria report, 2017 Available at- app.who.int/iris/ bitstream/10665/259492/1/9789241565523-eng.pdf

3. WHO. World malaria report 2014. Geneva: World Health Organization; 2014

4. Adikwu P, Amuta EU, Obande GA, Adulugba AO, Emmanuel A. Studies on Malaria Parasite and Haemoglobin Level among Pregnant Women Attending Antenatal at Benue State General Hospital, Otukpo, Nigeria. American Journal of Medicine and Medical Sciences 2017. 7(6): 265270. doi: 10.5923/j.ajmms.20170706.05.

5. Dawaki S, Al-Mekhlafi HM, Ithoi I, Ibrahim J, Atroosh, W. M., Abdulsalam AM, Lau YL . Is Nigeria winning the battle against malaria? Prevalence, risk factors and KAP assessment among Hausa communities in Kano State. Malaria Journal. 2016; 15: 351. http:// doi.org/10.1186/s12936-016-1394-3

6. Owoeye OD, Akinyemi JO and Yusuf OB. Decomposition of changes in malaria prevalence amongst under-five children in Nigeria. Malaria World Journal, 2018; 9:3

7. Bassey SE, and Izah SC. Some determinant factors of Malaria Prevalence in Nigeria. Journal of Mosquito Research 2017; 7(7): 48-58. doi: 10.5376/jmr.2017.07.0007)

8. This Nas FS, Yahaya A and Ali M. Prevalence of Malaria with Respect to Age, Gender and Socio-Economic Status of Fever Related Patients in Kano City, Nigeria. Greener Journal of Epidemiology and Public Health 2017; 5(5): 044049, http://doi.org/10.15580/GJEPH.2017.5.091017126 
9. Mgbemena IC, Ezea, CO, Ebe TE, Udensi UJ, Nwachukwu AA, Nzenwa DC, and Nwannah AL. Asymptomatic malaria among students of Federal University of Technology, Owerri (FUTO), Imo State, Nigeria. Biological Sciences and Pharmaceutical Research 2016. 4(6): 50-57 http:// www.journalissues.org/IBSPR/ http://dx.doi.org/10.15739/ ibspr.16.007

10. Obimakinde ET and Simon-Oke IA. The Prevalence of Malaria Infection among Patients Attending the Health Centre of the Federal University of Technology, Akure, Nigeria International Journal of Tropical Disease \& Health 2017; 27(4): 1-7, Article no.IJTDH.35340 ISSN: 22781005, NLM ID: 101632866

11. Adesina OO. Subclinical malaria infection among University of Maiduguri students: prevalence and parasite density. Malaria Journal 2013; 10(1):6-11

12. Matur .M, Azare B.A, Ugbong I. The Prevalence of Asymptomatic Malaria Parasitaemia amongst undergraduate students of University of Abuja. Nigerian Journal of Parasitology 2011. 22:44-52

13. Omolade O, Okwa D. and Adejoke CI . The malaria situation, perception of cause and treatment in a Nigerian University. Borno Malaria Journal 2010. 9(18):124

14. Mbanugo J.I, Emenalo S.E. Prevalence of malaria parasitaemia among blood donors in ' Owerri, Imo State, Nigeria Journal of Parasitology 2004. 25:75-80

15. Njilmah J.A, Ja'afaru A, Elkannah S.O, David D, Gbebi Y.V, Chintem D.G.W, Elkannah G.S and Danladi T. Malaria Parasite infections among school aged children in Jalingo and Sardauna Local Government Areas, Taraba State, Nigeria. Nigeria Journal of Parasitology 2019. 40 (2):158-162

16. Yakobo Nvahoga and Zanda Bochkaeva. Cross Study of Malaria Prevalence in History, Bed net utilization and Knowledge about the disease among Tanzanian college students. Malaria Research and Treatment, volume 2018, Article ID $8137051, \quad 5$ pages. http:// doi.org/10.1155/2018/8137051

17. Oluchi, Ezenwaka, C.O and Ivoh, C.J. Prevalence of malaria infection among students attending Federal University Otuoke Health Centre, Bayelsa State. International Journal of Basic Science and Technology 2018; 4 (1). 17-22.

18. Ummunnakwe F, Idowu E, Ajibade O, Etoketim B, Akindele S, Shokumbi A, et al., High cases of submicroscopic Plasmodium falciparum infections in a suburban population of Lagos, Nigeria. Malaria Journal 2019; 18:433

19. UkibeNkiru R, Nwabueze US, Onwubuya IE, Offia AK. Asymptomatic Plasmodium falciparum malaria infection in University Undergraduate students. Asian Journal of Bio- medical and Pharmaceutical Sciences 2019; 9:68

20. Adeyemo FO, Okpala PU, Nwakaego OE and Imoukhuede M. Malaria infections amongst students of the University of Benin, Edo state, Nigeria. International Journal of Recent Scientific Research 2014; 5(9): 1529-1532.

21. Anummudu CI, Adepoju A, Adediran O., Adeoye O, Kassim A,Oyewole I. and Nwuba RI. Malaria Prevalence and Treatment seeking behavior of young Nigerian adults. Annals of African Medicine 2006; 5(2): 82-88

22. Olusegun-Joseph T.S, Oboh M.A and UduakM.U . A survey of malaria prevalence and Anti-malarial preventive measures amongst students of University of Lagos, Nigeria. African Journal of Clinical and Experimental Microbiology 2016; 17(4):267-273

23. Oguntade E, Shamarina S, Meenakshii N, Lamidi-Sarumoh $A$ and Salari N. Statistical modelling of the effects of weather factors on malaria occurrence in Abuja, Nigeria. International Journal of Environmental Research and Public Health 2020; 17:3474

24. Nanvyat N., Mulambalah C.S, Barshep Y., Ajiji J.A, Dakul D.A and Tsingalia H.M. Malaria transmission trends and its lagged association with climatic factors in the highlands of Plateau State, Nigeria. Tropical Parasitology 2018; 8(1):1823

25. Aribodor DN, Njoku OO, Eneanya CI and Onyali IO. Studies on prevalence of malaria and Management practices of the Azia community, Ihiala L.G.A., Anambra State, South East Nigeria. Nigeria Journal of Parasitology 2003; 24:3338

26. Rahul K. Keswani and Jayesh R. Bellare. A Review of Mosquito Attraction Studies: Important Parameters and Techniques. Research Journal of Parasitology 2006; 1: 31 41.DOI: 10.3923/jp.2006.31.41

27. Oyinlola O, Mimiko T and Bensuoda A. A cross sectional study of Plasmodium infection: A hematological analyses of the blood samples. International Journal of Medicine and Medical Sciences 2015; 5(8) :274-277

28. Andrade B.B and BarralNeto M . Biomarkers for susceptibility to infection and disease severity in human malaria. MemInst Oswaldo Cruz, Rio de Janeiro 2012; 106: 70-78

29. Kamwi RN, Mfune J.K.E, Kaaya G.P and Jonazi J.B (2012). Seasonal variation in prevalence of malaria and vector species in Northern Namibia. Journal of Entomology and Nematology 2012; 4(5); 42-48

30. Idowu OA, Mafiana CF, and Sotiloye O. Traditional birth home attendance and its implication for malaria control during pregnancy in Nigeria. Trans. R. Soc. Trop Med Hyg. 102: 679-84 DOI: 10 1016/jrstmh 2008; 3:20 
31. Adebayo A.M, Akinyemi O.O and Cadmus E.O. Knowledge of malaria prevention among pregnant women and female care givers of under-five children in rural southwest Nigeria. Peer J 2015;3e792 DOI: 10 77I7/ peerj. 792

32. Oyetunde T. Oyeyemi, Akinwale F. Ogunlade and Isaac O. Oyewole. Comparative assessment of microscopy and rapid diagnostic test (RDT) as malaria diagnostic tools. Research Journal of Parasitology 2015; 10(3): 120-26

33. Ajumobi O, K Sabitu, P Nguku, J. Kwaga and G. Ntadom.
Performance of an HRP-2 rapid diagnostic test in Nigeria children less than 5 years of age. Am. J. Trop. Med. Hygeine 2015; 92:828-833

34. Garba B.I, Muhammad A.S, Musa A., Edem B., Yusuf I., Bello N.K, Adeniyi A.O and Kolawole T. Diagnosis of Malaria: A comparison between microscopy and rapid diagnostic test among under-five children at Gusau, Nigeria. Sub-Saharan African Journal of Medicine 2016; 3: 96101 